\title{
Succinct Manual for Proactive Teaching of Eating Disorders
}

\author{
New to Eating Disorders. Edited by Jane Morris and Caz Nahman; Cambridge University Press; \\ Cambridge, United Kingdom; 2020. ISBN 9781911623571; pp 96; \$ 25.99 (paperback)
}

\author{
Richard Balon ${ }^{1}$ (1) \\ Received: 29 December 2020 / Accepted: 9 February 2021/Published online: 15 March 2021 \\ (C) Academic Psychiatry 2021
}

Eating disorders are serious, difficult-to-treat mental illnesses with the highest mortality rate among all psychiatric disorders. However, training in the management of these disorders in various specialties, such as psychiatry, pediatrics, family medicine, and internal medicine, is usually insufficient [1, 2]. Psychiatry residents may be more knowledgeable about and comfortable treating eating disorders than residents of other disciplines [1]. Nevertheless, training opportunities in psychiatric residency, though more frequent than in other disciplines, are sparse. In one study [2], only 12 out of 113 responding psychiatry residency programs offered a scheduled rotation, and 24 offered an elective rotation. While the lack of rotation opportunities may be explained by the lack of specialized treatment programs for eating disorders in the USA and other countries, the remaining disquieting question is, "What and how do academic psychiatrists teach frontline psychiatrists and other specialists about the recognition and management of eating disorders in everyday practice?"

Two UK psychiatrists, Drs. Morris and Nahman, together with a group of seven of their colleagues, put together this resource book/teaching tool, which is "specially designed for experienced mental health clinicians, particular junior psychiatrists and those more senior colleagues working in general rather than eating disorders specialisms" (p. x).

This slim guide (96 pages, including index, which is quite refreshing) includes 12 brief chapters: What are eating disorders? (in this volume, anorexia nervosa, bulimia nervosa, and, briefly mentioned, avoidant restrictive food intake disorder); Causes of and formulation; The carer's perspective; Risk assessment and management; Ethical and medico-legal issues; Evidence-based treatments; Nutritional care-dietetic

Richard Balon

rbalon@wayne.edu

1 Wayne State University, Detroit, MI, USA interventions including behavioural interventions; Exercise and activity; Body image; SEED (severe and enduring eating disorders); Children and adolescents; and Managing transitions.

At this moment, the reader may think, "OK; good, succinct chapters and a couple of topics not usually covered in standard texts, but what is different about this book?" Its uniqueness is that this book was created for teaching. The idea is to provide a structured, supervisor-guided course (usually 1:1) for which this book is used as a starting point and resource. The authors write, "Our aim is to provide an illustrated syllabus to structured didactic supervision sessions. This resource is by no means a textbook but rather a series of stimuli to bring alive the basic principles of the specialty for the learner in the presence of an experienced supervisor or mentor. We seek not to replace the in-person teaching experience but to provide materials to structure and inform fruitful discussion" (p. x).

The authors suggest that the teaching process starts with the supervision contract (signed by both the supervisor and the trainee), which is printed in the book, with spaces for addressing specific issues such as number and frequency of sessions, how many modules or chapters will be covered in each session, and how much homework is expected. The individual chapters are structured as follows: Basic Summary of Specific Topic, followed by a few true/false questions to test oneself with explanatory answers; Key Points; Suggested Activities; References and Further Reading; and then space for writing "Notes and Reflections and Agreed Action" for the next time. In addition, the text uses many illustrative case vignettes.

The suggested activities are the most important component of study and homework. For instance, the suggested activities of the first chapter include a recommended article from the list of references ("it is a five minute read"): suggestion to watch a TED talk (YouTube link provided); setting aside an uninterrupted half hour to access the suggested website and to write down what was learned; reviewing The Royal College of 
Psychiatrists' module on eating disorders; and selecting a patient from one's current caseload whose illness is more complex and discuss it with the supervisor. The "in-between supervisory sessions structured homework" (with subsequent discussing during the next session) provides guidance on how to solidify continuous development of mastery of the given subject.

The text of the individual chapters is, in spite of the brevity, very informative. Some chapters bring readers' attention to the striking realities of eating disorders. For example, the authors mention that the mortality of anorexia nervosa is reported to be 5-10 times the standardized mortality rate. The chapter on the carer's (i.e., caregiver's) perspective cites a carer who wrote, "Nothing as a parent prepares you for the news that your child has an eating disorder," and the authors note that caring for a person with the binge-purge subtype of anorexia may be a greater burden on carers than taking care of a person suffering from schizophrenia, as marriages could be strained and siblings neglected. The chapter on nutritional care mentions the existence of a "group of patients accessing and contributing to 'pro-ana' (i.e., pro-anorexia) websites, sites that encourage the practice of anorexia behaviours" (p. 49). It also lists dietary changes practiced by patients with anorexia, such as overconsumption of fluids (increasing weight), reducing fluids, excluding particular food groups, and adapting socially acceptable diets (e.g., vegetarianism, veganism) to restrict range of foods, obsessive focus on supposed nutritional superiority or health-giving properties of some foods (i.e., orthorexia), reduction or omission of prescribed medications, and eating rituals (e.g., eating alone, eating only food cooked by themselves, eating slowly, cutting food into small pieces). Similarly informative is the chapter on exercise, which includes a discussion of compulsive exercise and why people over-exercise. I particularly liked the discussion of the parent role in the treatment of children and adolescents. The final chapter discusses transitions, such as to university, and some ways to protect patients during transitions (e.g., period of "parallel care" from both services, use of a patient-centered health record that goes with the patient).
A couple features could be considered weaknesses. The book reflects the British health system a bit, but it does use the nomenclature of the Diagnostic and Statistical Manual of Mental Disorders, Fifth Edition (DSM-5), and the core issues are the same or very similar in locales around the world. The only other weakness could be the chapter on ethical and medico-legal issues, as legal systems are quite different across locations. However, the supervisor of this course could adjust this part to a specific jurisdiction. As pointed out, different US states have different individual details regarding involuntary treatment, but many of the principles are common.

In my opinion, this is a very useful book that could be adopted by many programs which do not otherwise offer much education on eating disorders (perhaps the majority of programs [2]). It is easy and quick to read and provides a novel approach to active learning, using various stimuli, such as suggestions to go to websites with important materials, watch TED talks, or read important articles. Trainees, providing that they obtain the book, have spaces to write down notes and reflections based on their study and experience. In sum, this succinct manual presents a novel, proactive model for teaching about eating disorders, and I recommend it highly to all training programs.

\section{Declarations}

Conflict of Interest The author has no conflicts of interest.

\section{References}

1. Anderson K, Accurso EC, Kinasz KR, Le Grange D. Residents' and fellows' knowledge and attitude about eating disorders at an academic medical center. Acad Psychiatry. 2017;41:381-4.

2. Mahr F, Farahmand P, Bixler EO, Domen RE, Moser EM, Nadeem $\mathrm{T}$, et al. A national survey of eating disorder training. Int $\mathrm{J}$ Eat Disord. 2015;48:443-5.

Publisher's Note Springer Nature remains neutral with regard to jurisdictional claims in published maps and institutional affiliations. 